\title{
THE SYNTACTIC STRUCTURE OF AWGNI NOUN PHRASES
}

\author{
Berhanu Asaye Agajie
}

\author{
berhanuas@gmail.com \\ Injibara College of Teacher Education, \\ Ethiopia
}

\begin{abstract}
The objective of this study is to examine the syntactic structure of Awgni Noun Phrases. The assumption of Labeling Algorithm $\{\mathrm{XP}, \mathrm{H}\}$ is holding on, and an applied linguistic research design was employed to explore the intended objective. Data for this research were enriched by interviewing 12 native speakers of Awgni specializing in the proposed language. Through expert samplings, 20 Noun Phrases were selected and illustrated. Results showed that the Noun Phrases in Awgni could be formed out of the head Nouns all along through other lexical categories reminiscent of the Noun Phrases, Adjective Phrases, Verb Phrases, Determiner Phrases, and Adverb Phrases. These grammatical items were serving as dependents to the head Nouns. The head Nouns in Awgni are for all time right-headed. These heads are the only obligatory constituents, while the Phrasal categories are optional elements which could be either modifiers or complements to the head Nouns. In this regard, Labeling Algorithm explicitly chooses the contiguous Noun heads that are the label of the complete Syntactic Objects (SOs) anticipated for all Noun Phrase structures.
\end{abstract}

Keywords: Labeling Algorithm, Noun Phrase, Syntactic Object, $\{X \mathrm{P}, \mathrm{H}\}$

\section{INTRODUCTION}

Awgni is one of the different Agaw languages, ${ }^{1}$ Ethno-Cushitic, spoken typically in Amhara Regional State, currently known as Awi Administrative Zone and around Binshangul Gumuz region of Ethiopia (Berhanu, 2020; Desalegn, 2016; Esubalew, 2015). It is spoken by people of whom the greater parts are Orthodox Christians, not many Muslims, and very little Protestants. Most of the Awi people are farmers ${ }^{2}$ who are living in the rural neighborhood by cultivating

1 Hetzron (1969, P.1) informed that "the Agaw language) was once spoken in a very large area in the northern half of Ethiopia, but was gradually superseded by Semitic languages: Amharic and Tigrigna. The once continuous Agaw area is split into small islands that have escaped, so far, of semtization."

2 Murdock (1959, P.182) reminded that "it was widely reported in the literature Agaw are responsible for the evolution of traditional agriculture particularly in North part of Ethiopia. They mentioned as having cultivated varieties of plant such as tef, wheat, barley, nigerseed, lintees, flax and finger millet. These crops are assumed to have reached these people by diffusion from the Middle East." different types of crops $^{3}$ and whereas the majority of persons who subsist in the urban vicinity are merchants.

Various researchers (Berhanu, 2020; Haileluel, 1991; Hetzron, 1966, 1969; Palmer, 1959; Tadesse, 1984; Tadesse, 1988; Teferi, 2000; Yaregal, 2007) inspect diverse issues associated with Awi and Awgni language. Predominantly, Tadesse's (1984) "The Noun Phrase in Awgni" presented well description regarding noun morphology (gender, number and case inflections). He also discussed various inflectional elements within Noun Phrase. Not any of these studies look into how Labeling Algorithm (XP, $\mathrm{H}$ ) is relevant to look at the syntactic structure of Awgni Noun Phrases. Thus, this

3 According to Murdock (1959, P.182-183) "the Agaw improved the crops of which they borrowed and produced important varieties of sorghum. They also experimented with world plants in the search for new cultigens as the result of which the central highland Ethiopia, ranks with china, and India, as one of the world's important centers of origination of cultivated. They themselves apparently domesticated the donkey or ass and later learned to cross the horse to produce mule." 
study is concerned with structural assorted features of Syntactic Object representations established in the structure of Awgni Noun Phrases and aimed to design possible suggestions of this formation in favor of obtainable Problems of Projection (Chomsky, 2013, 2014, 2015).

The goal of proposed study is projected to narrow the gap by examining how Labeling Algorithm (XP, H) applies to look at the syntactic structure of Awgni Noun Phrases. ${ }^{4}$ As a result, this study as an applied linguist research is premeditated to explore how Labeling Algorithm is implemented to examine the syntactic structure of Awgni Noun Phrases. Therefore, it is promising to set this research finding into practice for authentic systematic language teaching program at college label.

\section{REVIEW OF LITERATURE}

The fundamental components of syntax are words (Carnie, 2013). They can be categorized into diverse lexical groupings depending on sense, morphological outward appearance, and syntactic connotation. It has been widely converse regarding in the literature (Arbib, 2012; Knott ,2012; Moro, 2014; Pulvermüller, 2014; Stout, 2010) is that natural language syntax and action grammar are corresponding in that both occupy hierarchical arrangements of various kind. Consequently, Wiltschko (2014) affirmed that phrases have a hierarchical representation in which words are coming together fruit fully into larger structural constituents.

Noun Phrase is a group of words that work together to name and describe a person, place, thing, or an idea. It joins

${ }^{4}$ The Labeling Algorithm in current study seems to significantly need the distinction between head and projection (Chomsky, 2013, 2015). It is "a special case of minimal search" seeking "heads $\mathrm{H}$ within its search domain" (Chomsky, 2014, P. 4). In this regard, current research in "the syntactic structure of Awgni Noun Phrases" is different in its approach, result, discussion and concluding remark from previous studies conducted by Josephat's (2007) and Cheng \& Rint (2014). together words into a larger component that is able to meaning as a sentence constituent (Marques, 2011). Noun Phrase can be judged as syntactic component that enclose more than single word and lacks the subject predicate connection. It holds some word arrangement elements that shape, the head word in different methods.

Phrasal groupings that can be conjoined with Noun Phrase are Verb Phrase, Noun Phrase, Adjective Phrase and Determiner Phrase (Chung, 2012; Marcotte, 2014). According to Carnie (2010) and Rauh (2010), the main belongings that differentiate all particular assortment of phrases and that create the function it participates are determined by the belongings of the head utterance that it comprises.

Noun Phrase structure is the fundamental component of syntactic examination, which is effortless to observe the parts of phrases and subparts of speech beneath phrase structure in a tree (Pullum, 2011). It seems that, syntactic tree allows to notice at a glance the hierarchical structure of Phrase. Structural reliance deals with the hierarchical structure, generally discovered in syntactic investigation by means of tree diagrams (Sag, 2010a, 2010b).

According to Chomsky (2013), computational scheme ought to be containing a Labeling Algorithm ${ }^{5}$ that searches SO to find out what type of an entity it is, observance to smallest look for. Optimally, all of the information appropriate to additional computation should be enclosed in a chosen negligible constituent; a head pinched beginning the lexicon (Collins \& Edward, 2016). The fundamental properties of natural language is that it permits a syntactic object (SO) to be bring together with another SO, forming a larger one, which can serve as the input for the assembling development again (Chomsky, Angel \& Dennis, 2017; Edith,

5 The Labeling Algorithm proposed by Chomsky (2013), when justified by a principle of legibility at the interface with semantics (Rizzi 2016), virtually imposes a many to one correspondence between syntactic labels and denotation types (Manabu, 2017). 
2019). ). The operation Merge in minimalism has been in use, whether absolutely or openly, to include two self-governing tasks: one is to merge two syntactic objects (SOs) and the other to choose which one of the two combined SOs to scheme or to develop into the label of the resultant structure (Thornton, 2016).

Chomsky (2013, 2014a, 2014b, 2015, 2015a) recommends that Merge $(X, Y)=\{X$, $Y$ \}. Suppose neither $X$ nor $Y$ is division of the other, as in merging read and the book to structure the syntactic object $\{X, Y\}$ matching to read the book. Presume that one is division of further; articulate $Y$ is division of $X$. As a result, the consequence of Merge is once more $\{X, Y\}$. Therefore, in syntactic structure, two items joined by the operation merge keen on an introverted set. Given that Merge is merely free, it depict upon every two items $X$ and $Y$ and generates an unordered twomember set (Chomsky, 2014, 2015; Murphy, 2015).

Each syntactic object realization in the interfaces ought to be labeled accordingly. In the course of labeling, every relevant constituent can receive a label from the syntactic Labeling Algorithm (Boökovî́, 2018a, 2018b; Chomsky, 2013, 2015, 2016; Ott, 2015; Rizzi, 2015; Smith, 2015).

Chomsky (2013, 2015) was introduced self-determining label-identifying operation, Labeling Algorithm (LA) which accredits Syntactic Objects. He argues that the operation labeling can be delayed. In his application, labels are determined by a Labeling Algorithm, which operates at the phase level along with other operations. This means that first, the phase structure is built and then at the phase level the whole phase is labeled (Mizuguchi, 2017; Narita, 2011; Saito, 2016; Takita, Nobu \& Yoshiyuki, 2016).

Syntactic Objects can be analyzed at the interfaces, working at the phase step all along with other operations (Edith, 2019; Shim, 2018; Stockwell, 2016). The pertinent information concerning $\mathrm{SO}$ will be supplied by a particular chosen element contained by it: a computational particle, to primary estimate Lexical Item (LI), a head. This LI must offer the label established by Labeling Algorithm, when the Algorithm be able to be relevant (Chomsky, 2013, 2013a, 2013b, 2014, 2015; Rizzi, 2016). Chomsky (2013, P.43) draw round how negligible investigation functions to discover the label of $\{\mathrm{H}, \mathrm{XP}\}$ case as he "suppose $\mathrm{SO}=\{\mathrm{H}, \mathrm{XP}\}, \mathrm{H}$ a head and $\mathrm{XP}$ not a head. Then minimal investigation will choose $\mathrm{H}$ as the label, and the usual procedures of understanding at the interfaces can proceed." In $\{\mathrm{H}, \mathrm{XP}\}$, minimal search instantly locates a Lexical Item $\mathrm{H}$ (a bundle of features, offered through the word list) and a two constituent set XP. It is being a lexical item, creates obtainable what substances to the interface systems. As a result, $\mathrm{H}$ is recognized as the label of $\{\mathrm{H}, \mathrm{XP}\}$. For that reason, categorization is carry out via negligible look for, consequently, when an agreed syntactic object SO consists of $\{X, Y P\}$, after that the head $X$ is singled out for the label of SO, as in $\{\mathrm{X}, \mathrm{XP}\}=\mathrm{X}$ (Adger, 2016; Narita, 2015; Rizzi, 2015a; Shlonsky and Rizzi, 2015).<smiles>[Y7][Y7]</smiles>

At this juncture, I projected that Awgni is the head final that it follows $Y=(X P, H)$. Thus, it is clear-cut as search into $Y$ yields a unique head $\mathrm{H}$. Then, it can be understood that $\mathrm{H}$ provides the label of $\mathrm{Y}$ in Noun Phrase structure. At this point, the closest head is straightforward in $\mathrm{SO}=\{\mathrm{XP}, \mathrm{H}\}$ since the structure contains a single head $\mathrm{H}$ that is least embedded. Therefore, LA can unambiguously identify it as the unique label of the structure (Shim, 2018).

The head is a great applicant to offer a label, as it is a lexical item (LI) that emerges from Lexicon through its syntactic group evidently distinct (Chomsky, 2013, 2014a, 2014b, 2015a; Rizzi, 2016). Given that the head $\mathrm{H}$, being a lexical item (LI), can right away provide a label for the entire structure, an object where a head is merged with a phrasal complement $\{\mathrm{XP}, \mathrm{H}\}$ constitutes the best case scenario for labeling. Thus, the operation Labeling Algorithm searches for the contiguous head $(X)$ inside the agreed $S O$. Accordingly, $X$ is the head and YP is considered as phrase as in: 


$$
\overbrace{\mathrm{YP}}^{\mathrm{XP}}
$$

YP in proposed model can be every phrasal group. Alternatively, the head provides the name to the component it produced Noun to Noun Phrase. Labeling Algorithm $\{\mathrm{XP}, \mathrm{H}\}$ places the head $\mathrm{H}$, and it will choose $\mathrm{H}$ as the label of the specified configuration (Elly, 2015; Epstein, Kitahara and Seely, 2014; Ott, 2015; Rizzi \& Cinque, 2015; Sobin, 2016).

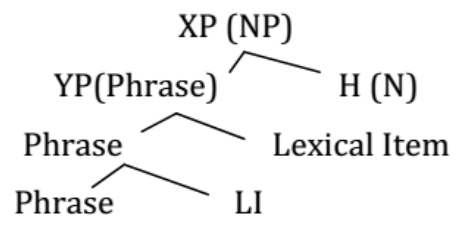

The preceding representation showed that the least embedded head is the Noun N. In this regard, all syntactic features represented in the above model are the properties of Lexical Items (Collins \& Stabler, 2016) that are visible to the syntax and can as a result, enter into syntactic relations.

The supposition that is understood in the examination, which I have accessible at this time is that, the tree structures of Noun phrase are built up from bottom to top fashion.

\section{METHOD}

The research design used in this study was applied linguistic type ${ }^{6}$ that is intending to resolve Labeling Algorithm problems in Awgni Noun phrase structures. It is planned to improve the quality of teaching within Awgni syntax in general, syntactic structure of Awgni Noun Phrases in advanced manner.

Through purposive sampling 12 (7 males, 5 females) Awgni language experts were interviewed to supplement the intended data. Additionally, expert sampling was used

\footnotetext{
${ }^{6}$ Applied linguistics is an interdisciplinary field which identifies, investigates, and offers solutions to language-related real-life problems in education (Brumfit, 1995). Thus, it is intending to put Labeling Algorithm $\{\mathrm{XP}, \mathrm{H}\}$ into practice to teach syntax and other related issues within Awgni language.
}

to capture the planned knowledge wellestablished in a particular shape of data in syntactic structure of Awgni Noun Phrases. Thus, 20 Noun phrases were chosen for intended analysis. The method of Noun Phrase examination employed in this study was operation Labeling Algorithm. I suppose $\{X P, H\}$ the set of Syntactic Object representation intended for Labeling Algorithm (LA) to be implemented on Noun Phrase structure. This was commenced on Merge of a phase head, looks for each constituent in its area for a label. In the simplest casing, the lexical item that head $\mathrm{H}$ in $\{X \mathrm{P}, \mathrm{H}\}$ representation will label a component. The study employs syntactic tree to help out the reader. ${ }^{7}$

\section{RESULT}

Noun Phrase is a phrasal constituent in set $\{X P, H\}$ whose head $\{H\}$ is a noun. Typically, it has the Noun (N) seeing that its innermost constituent. Noun phrase heads are words that function as the heads of Noun Phrases. A Noun Phrases consists of a noun or pronoun plus any determiners, modifiers, and complements. Only two grammatical forms can perform the function of Noun Phrases head in the English language. In the course of theoretical linguistics, the head or the nucleus of a Noun Phrase is the noun ${ }^{8}$ that determines the syntactic category of that phrase as in:

\section{(1) Ïnni walta safelka sïrasri yintuna \\ These six young children were coming \\ 'These six young children were coming'}

\footnotetext{
7 I will suppose, following Chomsky (2013, 2015), that syntactic trees have to be consistently labeled at the interfaces. As a result, a tree must be completely labeled. Regular labeling could be a consequence of interpretive principles, which need labels to properly interpret structure.

8 Literature in syntax (Beavers, 2003) has assumed that all Noun phrases are categorically headed by the Noun, with well-formedness categorical in nature (Christophe \& Christelle, 2017).
} 


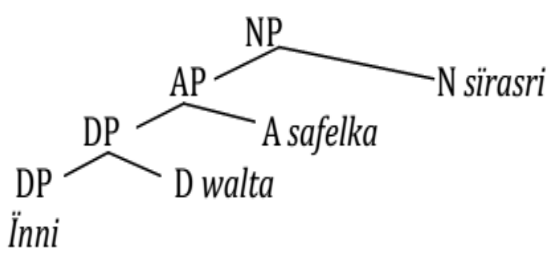

In (1) Labeling Algorithm (LA), initiated on Merge of a phase head sirasri, that search is the constituent ïnni walta safelka in its domain for the label. Ïnni is demonstrative word that is used to determine what the noun sirasri is referring to (Christophe \& Christelle, 2017). For example, ïnni walta safelka in the example above refers to sirasri that was just talked about in the discourse. Sirasri $(N)$ is the head of the overall Noun Phrase (NP) structure that has the immediate constituent inni walta safelka. This Adjective Phrase serves as the compliment. A demonstrative determiner inni (these) sits together with the Noun head sirasri. In Awgni, demonstrative determiner is or a pronoun that points to a particular noun or to the noun it replaces. For instance, ïnni is demonstrative that indicates the nearness of the head Noun sirasri. Likewise, the mathematical object walta (six) is used to count sirasri.

(2) Dïmmie coato seyixu aqqi ïnsixie ïnsaxistaw axno dibsixo

The red coat wears the man the work will do

The man wears the red coat says he will do the work

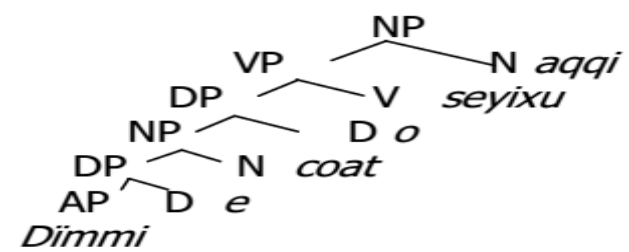

What tree notation in (2) tells us is that the overall expression dimmie coato seyixu aqqi is a Noun Phrase NP; its head is the Noun aqqi. The complement of it is the overall Verb Phrase dimmie coato seyixu. On the other hand, dimmie coato seyixu aqqi is a projection of the Noun aqqi.

Syntactic structures of Noun Phrases are hierarchically structured into successively larger set of dependent clause constituents belonging to a given category. In this regard, the subsequent data was revealing that dependent clause modifying the head
Noun kintantias in:

(3) Naka ŝelemïstïxu jegni yitopiyaw wotadri aylis desa

Today prized heroic Ethiopian

solder very happy

The Ethiopian heroic solder who prized today was very happy

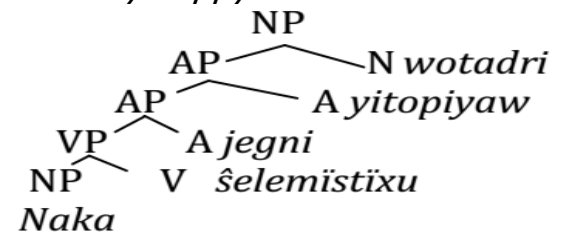

In the aforementioned Noun Phrase structure (3), the overall expression naka selemistixu jegni yitopiyaw wotadri is the Noun Phrase. Here minimal search immediately finds a lexical item wotadri as the head of entire Phrase structure (a bundle of features, provided by the lexicon). It is being a lexical item, makes available what matters to the interface systems. Thus, wotadri is identified as the label of \{naka selemïstixu jegni yitopiyaw, wotadri\}. Therefore, labeling is conducted via minimal search, so that when a given Syntactic Object consists of $\{\mathrm{XP}, \mathrm{H}\}$, subsequently, the head wotadri is picked out for the label of $\mathrm{SO}$, as in ( $\{$ naka šelemïstixu jegni yitopiyaw, wotadri\}) $=$ wotadri. The intended Noun Phrase structure encloses four constituents: the dependent clause Naka šelemïstixu, an Adjective Phrase jegni, Determiner Phrase yitopiyaw and the Noun Phrase wotadri.

Like yitopiyaw, all proper adjective in Awgni describes the head Noun. Yitopiyaw is the proper adjective that it is formed from proper noun yitopiya (Ethiopia). To further illustrate, consider that yitopiya is a proper noun because it is the name of a specific country. Nouns that are from Ethiopia are referred to as yitopiyaw, so the word yitopiyaw is a proper adjective.

(4) Yičo jewutux lïgdi amluw kïbis dadexïsta

Yičo bought the beautiful green dress stealing

'The beautiful green dress that Yičo bought was stealing' 


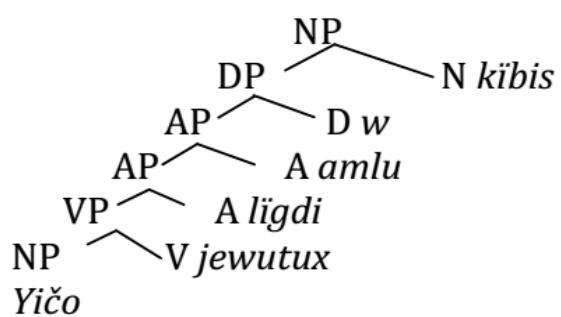

The tree notation used in (4) posits that, kibis is a head and Yičo jewutux is the Verb phrase, thus, minimal search assigns the structure of the category kibis. Furthermore, the Verb Phrase Yičo jewutux is merging with the Determiner Phrase ligdi amluw, and then Labeling Algorithm searches and chooses kibis as the label of the set \{Yičo jewutux ligdi amluw, kïbis\}.

(5) Ŝewentanti nargiw mïši ïnniku

Tasty honey mead this is

'This is tasty honey mead'

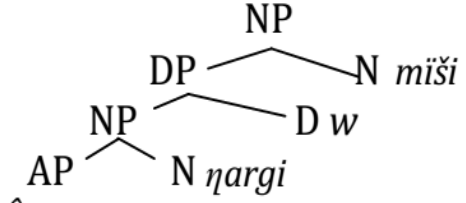

Sewentanti

What Phrase structure in (5) portrays us is that the overall expression sewentanti nargiw miši is a Noun phrase (NP); its head is the Noun miši. This head is being a lexical item that makes available which matters to the interface system. Thus, miši is identified as the label of \{ŝewentanti nargiw, miši\}. The Determiner Phrase sewentanti nargiw describes the Noun head miši. An Adjective Phrase sewentanti also modifies the head Noun miši. Therefore, sewentanti nargiw is the complement of the head Noun miši.

(6) Lïgdi fučči kïbis woysta Beautiful white dress sold 'Beautiful white dress was sold'

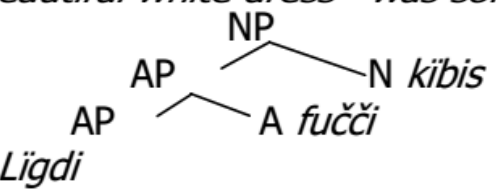

As shown in (6), for each Syntactic Objects, the most prominent lexical element within the label is the head Noun kibis. Hence, ligdi fučči kibis is the Noun Phrase. This is conjoining from Adjective Phrase ligdi, and another Adjective Phrase fučč and the Noun Phrase kibis.
(7)Ïnni balegka kïntantka yintekamagiyax

These rude students are coming

'These rude students are coming'

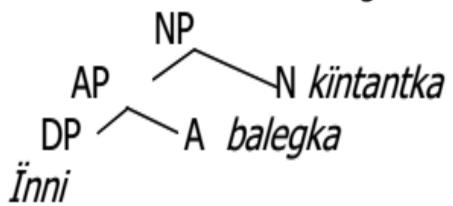

As analysis in (7) accounts that, ïnni balegka is the complement of the head kintantka. Thus, Labeling Algorithm employing minimal search chooses kintantka as the label of the set \{ïnni balegka, kintantka\}. İnni is a demonstrative, which indicates a specific Noun in a sentence. It refers the Noun that is near in space and time. When the Noun is omitted after ïnni, it becomes pronoun.

(8) Aylo lïqqa dïngulka nïseska kawenda zükuna

Very few giant animals in forest live

'Very few giant animals live in forest'

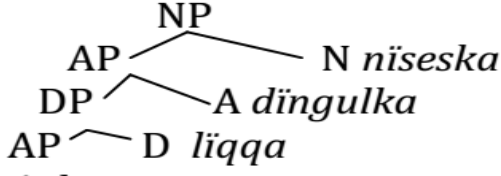

Aylo

The aforementioned structure (8) depicts that, there are four phrases: the Adjective aylo, the Determiner liqqa, the Adjective Phrase Aylo liqqa dingulka and the Noun Phrase Aylo liqqa dingulka nïseska. The Determiner Phrase aylo liqqa conjoins with Adjective Phrase aylo liqqa dingulka immediately followed by the Noun Phrase Aylo liqqa dingulka nïseska. The head of the overall phrase structure is the Noun nïseska.

(9) Dïnguli sarki gïbači duntuxa Big black jar broken

'Big black jar was broken'

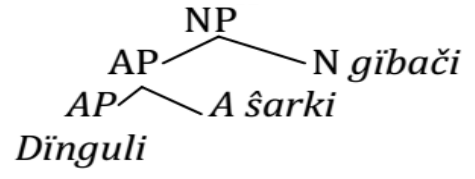

The analysis in (9) claims that, dinguli sarki gïbači is the Noun Phrase. The Labeling Algorithm, initiated on Merge of the intended phase head gïbači, searches each constituent dinguli sarki in its domain for a label. In the simplest case, the lexical item that head \{dinguli sarki, gïbačl\} was label constituent. Adjective Phrase dinguli sarki is the 
complement of the Noun gïbači.

(10) An malne buzi giŝsisini yintamagiyax

That extremely fat trader coming is

'That extremely fat trader is coming'

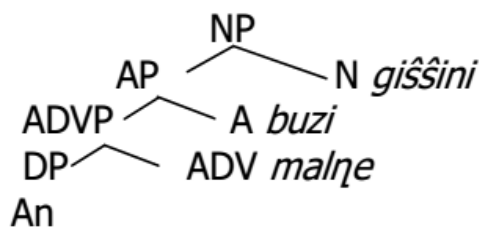

In the structure such as (10), there exists the construction an malne buzi, giŝsinini\}, is the Phrase and the Head. The head giŝsini gives the name to the constituent it generates as Noun to Noun Phrases NP. An malne buzi is the complement of the head Noun gisssini.

\section{(11) İn dïkki ligisimi Tadel dibtiniyax}

This bad tall man talkative

'This bad tall man is talkative'

In

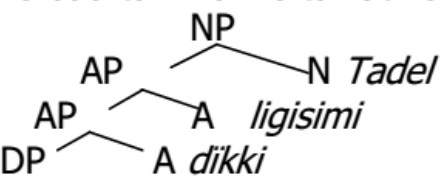

In (11), there are two adjectives (dikki and ligisimi) that modify the head Noun Tadel. The adjective denoting the projected value precedes that signaling dimension. Speaker seems to explain that the character of an individual was more important than his looks, and that elucidates why the value adjective occurs closest to the head Noun. Operation labeling in this regard says is that every merge constitutes a phase; as one expects labeling operate after each merge. Then Labeling Algorithm chooses Tade/ as the label, and the normal measures of clarification at the interfaces can carry on. As a result, Tade/ is the Noun head that is conjoined with Adjective Phrase in dikki ligisimi.

Multiple adjectives that can take place as modifiers in Noun Phrase structure could come from same semantic class. When that occurs, the order remains the privilege of the speaker; in general depending on effortlessness of producing them, and also which of the adjectives the speaker wants to emphasize.

In many cases, the adjective when the speaker wants to underline is placed closest to the head as in:

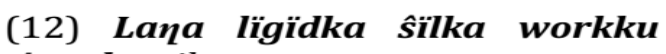
tivanka yikuyax

Two beautiful little gold rings are mine

Two beautiful little gold rings are mine

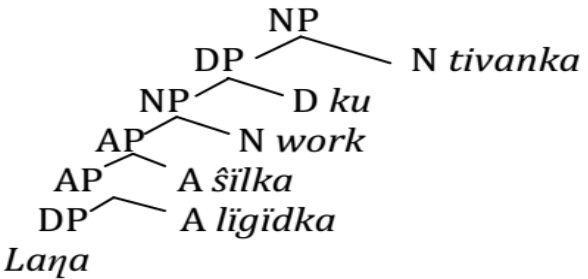

What (12) tells us is that the overall expression \{lana ligïdka sillka workku, tivanka\} has the Phrase and the head. The head tivanka gives the name to the constituent. The above projected tree provides a visual representation of the constituent structure of Noun Phrase lana ligïdka silka workku tivanka. Thus, tivanka is the head of the Noun Phrase; lana ligïdka sillka is Adjective Phrase that functions as the complement of the head word. The cardinal lana indicates the precise number of referent.

(13) Yizikuwi kïbeb fučči sat dunta

The heavy round white watch was broken 'The heavy round white watch was broken'

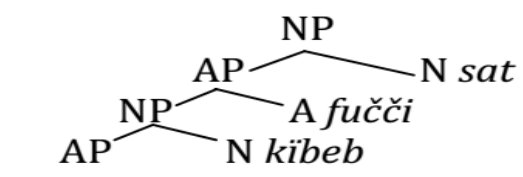

Yizïkuwi

In (13), the head sat is conjoining with the complement yizikuwi kibeb fučči. In this regard, constituents conjoined with head sat are Noun Phrase yizikuwi kibeb, and Adjective Phrase yizikuwi kïbeb fučči.

Awgni expresses ordinal numerals with a periphrastic construction. Ordinal numbers are expressed by a relative clause. It is therefore, the relative clause that modifies the noun in the capacity of an ordinal. The relative clause is marked by the relative indicator anti, and has the relevant cardinal number as in:

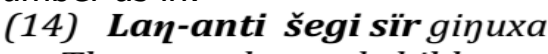

The second good child running

'The second good child was running' 


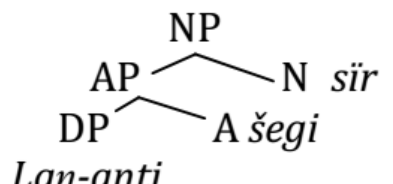

Lan-anti

An analysis such as (14) accounts us is that sir is being a phrasal head; Labeling Algorithm (XP, $\mathrm{H})$ takes sir as the label. Thus, Determiner lan-anti and Adjective Phrase šegi are modifying the prearranged Noun Phrase sir.

Quantifier in Awgi is a kind of determiner under Noun Phrase structure which denotes inaccurate quantity. It is a word that frequently goes earlier than a Noun to articulate the amount of the object; for example, liqa xoši la little milk. Most quantifiers are followed by a Noun. It is also possible to use them without the Noun when it is clear what I am referring to as in:

(15) Menč ïlluwawu xoši ï̈nda zïko

Some cow milk in the house there is

'There is some cow milk in the house'

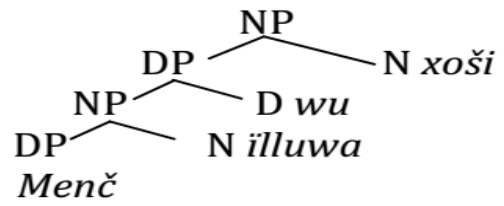

According to (15) menč illuwawu xoši is the Noun Phrase. The head of the overall Phrase structure is xoši. Another modifier is existing, namely the immediate Determiner Phrase menč illuwawu that serves as complement for Noun head xoši.

Quantifiers in Awgni can modify plural nouns; they include: liqqa/ few, menčka/ many and wulla/ all. The syntactic property of this type of quantifier is illustrated in (16). In this example, the quantifier indicates the quantities of the noun it modifies although no precise amount is given. However, it is not obligatory element in a syntactic structure of Awgni Noun Phrase.

\section{(16) Menčka dedeqka kïntantka}

kïntinnašo kasuna

Many short students to school went

'Many short students went to school'

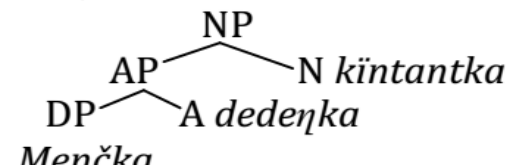

The analysis in (16) claims that Labeling Algorithm picks the Noun kintantka as the label, and the common actions of analyzing at the interfaces can proceed. Hence, kintantka is the head of the overall phrase structure and its complement is the Noun Phrase menčka dedenka.

Furthermore, the proximal singular demonstrative determiner is conjoined within Noun Phrase as in (17):

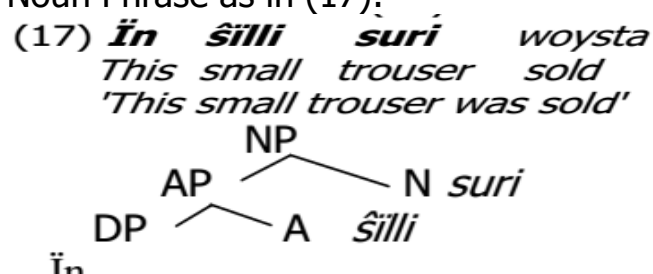

The notation in (17) informs that in siilli suri is the Noun Phrase. The head of the overall Noun Phrase is suri. This head projects the resulting object. Since, in and silli are Lexical Items (LI), and subsequently both in (DP) and silli (AP) can be the label of the resulting structure. Combinations of these lexical elements consist of a functional element and it determines the category of the combination.

It ought to be noted that, the use of the plural demonstrative requires number agreement with the Noun head, the adjective and the numeral as in:

(18) Ani soxeta dïngulka bera woystika

Those eight huge oxen were sold

'Those eight huge oxen were sold'

Ani

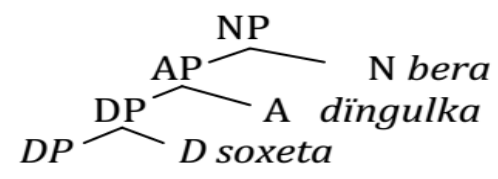

The Noun Phrase structures demonstrated under the analysis in (18) are the demonstrative (ani), the numeral (soxeta), an adjective (dingulka) and noun (bera) in that order. The head of the Noun Phrase bera was conjoined with Adjective Phrase ani soxeta dingulka. As demonstrated above, Adjective Phrase dingulka is the immediate complement for Noun Phrase bera. The quantifier ani modifies plural Noun bera. The cardinal soxeta indicates the precise number of oxen. The combination of 
dingulka and bera consist of a functional element that determines the category of the alignment.

(19) Dïnguli wuljij tïripizi dunta The big old table broken 'The big old table was broken'

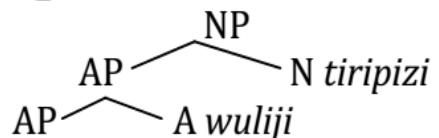

Dïnguli

Phrase structure in (19) utters that the Noun Phrase tiripizi (head) conjoins with the Adjective Phrase complement dinguli wuliji. Moreover, wuliji is the immediate complement for the Noun head tiripizi.

(20) Waŝini skawi bürčïqu duntux?

Which new glass broken

'Which new glass was broken?'

Waŝini

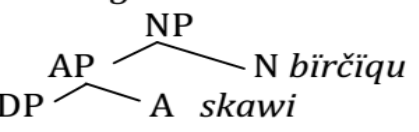

The output representation in (20), waŝini skawi bïrčiqu is the Noun Phrase. The Noun birčiqu is the head of the phrase structure. It conjoins with Adjective phrase waŝini skawi. Birčiqu is the head of the overall Phrase structure. Then Labeling Algorithm decides birčiqu as the label, and then the typical procedures of rationalization at the interfaces can carry on.

\section{DISCUSSION}

Comparable to Wiltschko (2014) research finding, Awgni Noun Phrases have a hierarchical drawing in which words are clustered jointly in to productively larger structural components. Corresponding to Chung 2012), Kayne (2010), and Marcotte (2014) studies, phrasal categories conjoined within Awgni Noun phrase include: Noun Phrase (NP), Verb Phrase (VP), Adjective Phrase (AP), Adverb Phrase (ADVP) and Determiner Phrase. The same as Chomsky (2015) and Murphy (2015) two items in Awgni Noun Phrases were joined by the operation merge into a solitary set. In this regard, similar to Chomsky's (2013, 2015) Labeling Algorithm analysis, each Syntactic Object in existing study have to be labeled, and introduces a self-determining label recognizing operation Labeling Algorithm.
Close to Chomsky (2013) the simplest supposition in present research is that; Labeling Algorithm is just minimal search, most probably appropriating a third factor rule, as in Agree and other operations. In the preeminent case, the relevant information concerning Syntactic Object (SO) was accessible through a solitary selected element within it: a computational atom, to first estimated a Lexical Item (LI), a head. This LI is invented to present the label established by Labeling Algorithm, when the Algorithm be able to apply.

Chomsky (2013, 2014, 2015) presumes $\mathrm{SO}=\{\mathrm{H}, \mathrm{XP}\}, \mathrm{H}$ a head and XP not $\mathrm{a}$ head. Then negligible search will choose $\mathrm{H}$ as the label, and the customary events of understanding at the interfaces can carry on. On the other hand, Awgni is head ending that pursues the structure $\mathrm{SO}=\{\mathrm{XP}, \mathrm{H}\}$, where $\mathrm{H}$ is a head and XP is any phrase, negligible look for will allocate the structure of the group $\mathrm{H}$. The operation LA searches for the adjoining head $(X)$ within the agreed SO, where closest means least rooted in the given structure.

Finally I will suggest that highly developed study on how Labeling Algorithm $\{X$, $Y$ \} provides to label Syntactic Object representations contained by Phrase structures in Awgni.

\section{CONCLUSSION}

Study verified that a head combined by the means of phrase $\{X P, H\}$; LA overtly decides the neighboring head, $\{\mathrm{H}\}$ as a label of the complete Syntactic Object. Thus, in assessment, $\mathrm{H}$ belongs to the Noun head. Subsequently, Labeling Algorithm chooses $\mathrm{H}$ as the label and the standard events of understanding at the interface can carry on. Thus, the head Noun in Awgni provides the name to the constituent it produces.

On the other hand, in $\{\mathrm{XP}, \mathrm{H}\}, \mathrm{XP}$ can be any Syntactic Object such as Noun Phrase, Adjective Phrase, Adverb Phrases, Verb Phrase and Determiner Phrase. The Noun Phrases in Awgni can be constructed out of head Nouns $\{\mathrm{Hs}\}$ collectively with Phrasal categories. In this regard, all lexical grouping modifying the head Nouns restrictively, and they are appointed to 
confine the potential reference of the modified Nouns in the same way.

\section{REFERENCES}

Adger, D. (2016). A labeling solution to a curious EPP effect. London: Queen Mary University.

Arbib, A. (2012). How the Brain Got Language: The Mirror System Hypothesis. Oxford: Oxford University Press.

Beavers, J. (2003). More Heads and Less Categories: A New Look at Noun Phrase Structure. In Muller, Stefan (Ed.), Proceedings of the 10th International Conference on Head-Driven Phrase Structure Grammar, Michigan State University, 47-67. Stanford, CA: CSLI Publications.

Berhanu, A. A. (2020). Syntactic Object Representation found in Awgni Sentences. OKARA: Jurnal Bahasa dan Sastra, 14 (1), 99-116. DOI: 10.19105/ojbs. v14i1. 3226

BoökoviÊ, Z. (2018a). On Movement out of Moved Elements, Labels, and Phases. Linguistic Inquiry, 49 (2), 247-282.

BoökoviÊ, Z. (2018b). On the Coordinate Structure Constraint, Across-the-Board Movement, Phases, and Labeling. Ms., University of Connecticut.http://ling.auf.net/lingbuzz/ $003894 \dot{I}$.

Brumfit, C. J. (1995). Teacher Professionalism and Research. In G. Cook \& B. Seidlhofer (eds.), Principle and Practice in Applied Linguistics. Oxford: Oxford University Press.

Carnie, A. (2010). Constituent structure. Oxford: Oxford University Press.

Carnie, A. (2013). Syntax: a generative introduction. Oxford: wily Blackwell.

Cheng L., \& Rint, S. (2014). The Syntactic Structure of Noun Phrases. https://www.researchgate. net/ publication/277938226

Chomsky, N. (2013). Problems of Projection. Lingua, 130, 33-49.

Chomsky, N. (2013a). Notes on Denotation and Denoting. In Caponigro, Cecchetto, C (eds.) From Grammar to Meaning and I: The Spontaneous Logicality of Language. Cambridge: Cambridge University Press, 38-46. http:// dx.doi. org / 10.1017/ CBO9781_139519328. 004

Chomsky, N. (2013b). Problems of Projection. Lingua, 130, 33-49. http:// dx.doi. org/10.1016 / j.lingua. 2012.12.003

Chomsky, N. (2014). Problems of Projection: Extensions. Ms. Chomsky, N. (2014a). Problems of Projection: Extensions. Ms., MIT. Chomsky, N. (2014b). Lectures on syntax at MIT. http: // whamit. mit. edu/ 2014/ 06/ 03/ recent linguistics-talks-by-chomsky/

Chomsky, N. (2014a). Problems of Projection: Extensions. Ms., MIT.

Chomsky, N. (2014b). Lectures on syntax at MIT. http:// whamit. mit.edu/ 20 14/ 06/03/recent linguistics-talks-by-chomsky

Chomsky, N. (2015). Problems of projection: Extensions. In Elisa Di Domenico, Cornelia Hamann \& Simona Matteini (eds.), Structures, strategies and beyond - studies in honour of Adriana Belletti, 3-16. Amsterdam \& Philadelphia: John Benjamins.

Chomsky, N. (2015a). Preface to the 20th-anniversary edition. The Minimalist Program. Cambridge, MA: MIT Press, viixiv.

Chomsky, N. (2016). "Puzzles about Phases." In Linguistic Variation: Structure and Interpretation. Contributions in Honor of M. Rita Manzini, ed. Ludovico Franco, Paolo Lorusso, and Giulia Bellucci. Berlin: De Gruyter.

Chomsky, N., Ángel, G., \& Dennis, O. (2017). Generative Grammar and the Faculty of Language: 
Insights, Questions, and Challenges. http:// ling.auf. Net/lingbuzz/003507

Christophe, P., \& Christelle, M. (2017). Determiners. https: // halshs. Archives ouvertes.fr/halshs 01666846

Chung, S. (2012). Are lexical categories universal? The view from Chamorro. Theoretical Linguistics, $38,(1-2), 1-56$.

Collins, C., \& Edward, S. (2016). A Formalization of Minimalist Syntax. Syntax, 19(1), 43-78.

Desalegn, A. (2016). An Ethnographic Introduction to the Kumpal Agaw. Journal of Ethiopian Studies, 49, 35-56.

Edith, A. (2019). Labeling and verb-initial word order in Seediq. Journal of East Asian Linguistics, 28(4), 359-394.

Elly, G. (2015). Where are the parameters in Problems of Projection? ICHL 22.

Epstein, S., Kitahara, H., and Seely, D. (2014). Labeling by Minimal Search: Implications for Successive- Cyclic A-movement and the Conception of the Postulate Phase. Linguistic Inquiry, 45 (3), 463- 481. http:// dx. doi. org/10. 1162/ LING_a_001 63

Esubalew, A. (2015). "Developing Awgni-Amharic Cross-Language Information Retrieval (CLIR): A Dictionary Based query Translation Approach." Msc thesis. Gondar University.

Haileluel, Y. (1991). "Verb Complementation in Awgni." MA Thesis. Addis Ababa University.

Hetzron, R. (1966). The Verbal System of Agau. PhD Dissertation. Lo Angeles: University and California.

Hetzron, R. (1969). The Verbal System of Southern Agaw. Berkeley: University of California Press.

Josephat, R. (2007). The Structure of the Bantu Noun Phrase. SOAS Working Papers in Linguistics, 15, 135-148.

Kayne, R. (2010). Antisymmetry and the lexicon. In Anna Maria Di Sciullo and Cedric Boeckx, eds., The Biolinguistic Enterprise., Oxford, UK: Oxford University Press, 329-353.

Knott, A. (2012). Sensor motor Cognition and Natural Language Syn tax.Cambridge, MA: MIT Press.

Manabu, M. (2017). Labelability and Interpretability. Studies in Generative Grammar, 27(2), 327-365.

Marcotte, J. (2014). Syntactic categories in the correspondence architecture. In Miriam Butt \& Tracy Holloway King (eds.), Proceedings of the LFG14 Conference, Stanford, CA: CSLI Publications, 408-428.

Marquez, M. (2011). Working with words: An Introduction to English linguistics. Valencia: Universities de Valencia.

Mizuguchi, M. (2017). Labelability and interpretability. Studies in Generative Grammar, 27-2, 327365.

Moro, A. (2014). On the similarity between syntax and actions. Trends in Cognitive Sciences, 18, $109-110$.

Murdock, P. (1959). Africa: Its People and Their Cultural History. New York. McGraw-Hill Book Co. Inc.

Murphy, E. (2015). Reference, Phases, and Individuation: Topics at the Labeling-Interpretive Interface. Option, 1826, 17 (5), 1-13. Doi.org/10. 5334/opt.cn

Narita, H. (2011). Phasing in Full Interpretation. PhD dissertation. MIT Press.

Narita, H. (2015). Proceedings of the $32^{\text {nd }}$ West Coast Conference on Formal Linguistics, ed. Ulrike Steindl et al., 286-295. Somerville, MA: Cascadilla Proceedings Project.

Ott, D. (2015). Symmetric Merge and Local Instability: Evidence from Split Topics. Syntax, 18, 157 200.

Palmer, F. (1959). The verb classes of Agaw (Awiya). Mitteilungen des Institu ts fuer Orien tforschung, 7, 270-297. 
Pullum, G. (2011). On the mathematics of Syntactic Structures. Journal of Logic, Language and Information, 20, 277-296.

Pulvermüller, F. (2014). The syntax of action. Trends in Cognitive Sciences, 18, 219-220.

Rauh, G. (2010). Syntactic categories. Oxford: Oxford University Press.

Rizzi, L. (2015). Labeling, maximality, and the head - phrase Distinction. The Linguistic Review, 33(1), 103-127. https:// doi.org/ 10.1515/tlr-2015-0016.

Rizzi, L. (2015a). Cartography, criteria, and labeling. In Ur Shlonsky (ed.), beyond the functional sequence, 314-338. New York: Oxford University Press.

Rizzi, L. (2016). Labeling, maximality, and the head-phrase Distinction. The Linguistic Review, 33(1), 103-127.

Rizzi, L., \& Guglielmo, C. (2016). Functional categories and syntactic theory. The Annual Review of Linguistics, 2(13). Doi: 10.1 146/annurevlinguistics -011415-040827

Sag, I. (2010a). English filler gap constructions. Language, 86, 486-545.

Sag, I. (2010b). Feature geometry and predictions of locality. In Features: Perspectives on a Key Notion in Linguistics (ed. A. Kibort and G. G. Corbett), Oxford University Press, 236-271.

Saito, M. (2016). (A) Case for Labeling: Labeling in languages without $\varphi$-feature agreement. The Linguistic Review, 33, 129-175.

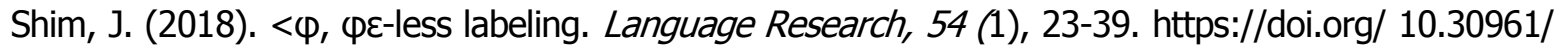
Ir.2018.54.1.23

Shlonsky, U., \& Luigi, R. (2015). Criterial Freezing in small clauses and copular constructions in Italian and Hebrew. Ms., University of Geneva, University of Siena.

Smith, W. (2015). A Labeling Approach to Constraints on Coordinate Structure Syntax. Ms., University of Arizona. http:// ryanwaltersmith.wix site.com/home/ papers $I$.

Sobin, N. (2016). The EPP as Argument Structure Requirements on Functional Verbal Heads. Published by Sciedu Press.

Stockwell, R. (2016). Labeling in Syntax. Cambridge Occasional Papers in Linguistics, 9, 130-155.

Stout, D . (2010). Possible relations between language and technology in human evolution. In April Nowell \& Iain Davidson (ed.), Stone Tools and the Evolution of Human Cognition, 159-184. Boulder, CO: University Press of Colorado.

Tadesse, M. (1984). "The Noun Phrase in Awgni." MA Thesis. Addis Ababa University.

Tadesse, T. (1988). 'Process of Ethnic Interaction and Integration in Ethiopian History: the Case of Agua' Proceedings of the ${ }^{\text {9th }}$ International Coverage of Ethiopian Studies, Moscow: Nauka Publisher, 6, 192-206.

Takita, K., Nobu, G., \& Yoshiyuki, S. (2016). Labeling through spell-out. The Linguistic Review, 33, 177198.

Teferi, G. (2000). "An Analysis of Awngi Proverbs." MA Thesis. Addis Ababa University.

Thornton, C. (2016). Three ways to link merge with hierarchical concept combination. Biolinguistics, $10,78-106$.

Wilts chko, M. (2014). The Universal Structure of Categories. Cambridge, Cambridge University Press.

Yaregal, A. (2007). "Case in Awngi." MA Thesis. Addis Ababa University. 